\title{
Adding PD-1/PD-L1 Inhibitors to Chemotherapy for the First-Line Treatment of Extensive Stage Small Cell Lung Cancer (SCLC): A Meta-Analysis of Randomized Trials
}

\author{
Francesco Facchinetti ${ }^{1}$, Massimo Di Maio ${ }^{2, *(D)}$ and Marcello Tiseo ${ }^{3,4}$ (D) \\ 1 Predictive Biomarkers and Novel Therapeutc Strategies in Oncology, Inserm U981, Gustave Roussy Cancer \\ Campus, Paris-Saclay University, 94800 Villejuif, France; FRANCESCO.FACCHINETTI@gustaveroussy.fr \\ 2 Department of Oncology, University of Turin, at Ordine Mauriziano Hospital, 10128 Torino, Italy \\ 3 Department of Medicine and Surgery, University of Parma, 43126 Parma, Italy; marcello.tiseo@unipr.it \\ 4 Medical Oncology Unit, University Hospital of Parma, 43126 Parma, Italy \\ * Correspondence: massimo.dimaio@unito.it
}

Received: 23 July 2020; Accepted: 14 September 2020; Published: 16 September 2020

Simple Summary: Treatment strategies in advanced, metastatic small cell lung cancer have been recently implemented by the combination of chemotherapy and immunotherapy. Nevertheless, the magnitude of survival benefit observed in clinical trials does not reproduce the major improvements observed in non-small cell lung cancer and other malignant diseases. By performing a systematic review and gathering the available data in a meta-analysis, we aim to compare the outcomes of patients treated with standard chemotherapy alone or with PD-1/PD-L1 inhibitors immunotherapy across clinical trials, in order to sustain treatment decisions. The addition of PD-1/PD-L1 inhibitors to standard chemotherapy improves all activity and efficacy outcomes, with a manageable safety profile. The benefit in overall survival is more evident if considering long-term analysis, compared to median estimations.

\begin{abstract}
Survival outcomes in extensive-stage small cell lung cancer (ES SCLC) are dismal, with median overall survival (OS) less than 12 months. The combination of PD-1/PD-L1 immune checkpoint inhibitors (ICIs) with first-line platinum-etoposide chemotherapy has been recently evaluated in randomized clinical trials. We performed a systematic literature review through PubMed and conference proceedings. Randomized trials evaluating chemotherapy +/- PD-1/PD-L1 ICIs were included in the meta-analysis. Efficacy (OS), activity [progression-free survival (PFS) and objective response rate (ORR)] outcomes and toxicities were analyzed. For selected endpoints, we focused on patients' subgroups (OS) and on landmark analyses (OS, PFS). Four randomized trials were identified; globally, 1553 patients were randomized to receive chemotherapy +/- PD-1/PD-L1 ICIs. Adding a PD-1/PD-L1 ICI to chemotherapy led to a significant benefit in OS [hazard ratio (HR) 0.76 , 95\% confidence interval (CI) $0.68-0.85$, $p<0.00001$ ), PFS [HR 0.75, 95\% CI 0.68-0.84, $p<0.00001$ ] and ORR [odds ratio 1.28, 95\% CI 1.04-1.57, $p=0.02]$. No unexpected toxicity emerged. At 12, 18, 24 months for OS, and at 12, 18 months for PFS, experimental arms retained significant improvement in event-free rates, with absolute gain of approximately $10 \%$ compared with standard treatment. Albeit the magnitude of the benefit is less impacting compared to other settings of immunotherapy, the addition of PD-1/PD-L1 ICIs to chemotherapy in ES SCLC provided significant improvements in survival outcomes with the known toxicity profile. Biomarkers predicting which patients are suitable to derive long-term benefits are eagerly awaited.
\end{abstract}

Keywords: small cell lung cancer (SCLC); immunotherapy; first-line chemotherapy; meta-analysis; PD-1/PD-L1 


\section{Introduction}

Small cell lung cancer (SCLC) is a poorly differentiated neuroendocrine neoplasm accounting for about $15 \%$ of lung malignancies [1]. Its peculiar clinical features are represented by the strong etiopathogenic association with smoking history, the central thoracic localization and the rapid proliferation index, impacting on the highly symptomatic forms often observed already at disease diagnosis [2]. Synchronous and metachronous metastatic spread to lymph nodes, brain, liver and bone is frequent.

SCLC high proliferation index defines this tumor as chemo- and radio-sensitive, as rapid, relevant and symptomatic disease regression with chemotherapy $+/$ - radiotherapy are normally achieved (the combination of the two treatments being administered with curative intent in limited-stage forms, LS SCLC). Nevertheless, in extensive-stage (i.e., metastatic, ES SCLC), disease progression is virtually unavoidable, with a median progression-free survival (PFS) shorter than six months [3]. Second-line treatment options are limited and globally disappointing, as chemo-resistance rapidly occurs, with response rates rarely exceeding 15-20\% [4-6]. Median overall survival (OS) estimations in clinical trials of ES SCLC are therefore dismal, being approximately 10 months (since first-line initiation) [3].

For decades, platinum-etoposide has been the regimen of choice for SCLC patients, followed by second-line topotecan $[4,5]$. The outcomes of ED SCLC have been poorly improved by additional strategies such as prophylactic cranial irradiation (PCI, standard of care in LD) and consolidation thoracic radiotherapy, both of them controversial issues in ED SCLC management [7,8]. Additional strategies, such as maintenance therapies or the addition of anti-angiogenic agents to first-line treatment, failed to provide significant survival improvements $[9,10]$.

SCLC immunogenicity has been evoked by (i) the expression of PD-1/PD-L1 detected in SCLC samples, especially in immune cells present in the stroma [11]; (ii) its strict correlation with smoking exposure, causing non-synonymous mutations therefore turning out in high tumor mutational burden (TMB) [12]; (iii) auto-antibodies cross-reacting with the neuronal antigen present in $16 \%$ of SCLC patients, leading to auto-immune paraneoplastic syndromes in approximately $5 \%$ of the cases $[13,14]$. To the detriment of initial enthusiasms [15], the first clinical proofs of PD-1/PD-L1 immune checkpoint inhibitors (ICIs, combined or not with CTLA-4 ICIs) have been disappointing in the pretreated setting of SCLC and as switch-maintenance strategies, frustrating, in addition, the role of PD-L1 as a biomarker [16-19]. Nevertheless, a subset of patients responded to the anti-PD-1 agent nivolumab or pembrolizumab when administered as the third or later treatment line (response rates $12-20 \%$ ) and experienced very prolonged responses, as median durations of response were 17.9 months and not-reached (after 7.7 months of follow-up), respectively [20,21].

Similar to studies conducted in advanced NSCLC, anti-PD-1/PD-L1 ICIs have been evaluated in combination with platinum-etoposide chemotherapy for the first-line treatment of ED SCLC. Here, we provide a systematic review and meta-analysis of randomized clinical trials evaluating the addition of PD-1/PD-L1 ICIs to first-line chemotherapy in SCLC.

\section{Results}

\subsection{Characteristics of the Trials}

The selection process of trials eligible for the meta-analysis is reported in Figure S1. In the search performed in June 2020, three trials were found eligible for inclusion [22-24]. A further publication reported updated toxicity and quality of life measures of one eligible trial [25]. In addition, four eligible trials were identified when searching the proceedings of the main International meetings, three of them representing presentations of trials already identified in PubMed, whereas one new study was identified [26-29].

Analysis of study quality was feasible for the three trials published in extenso [22-24] and only partially for the study still not published in extenso [29]. With this limitation, most of the evaluation 
criteria for the study quality checklist were fulfilled, with an overall quality score of B1 (sufficiently high quality to consider the risk of bias as low to moderate) for all included studies.

The main characteristics of the four trials included in the meta-analysis are reported in Table 1: one trial each with the PD-L1 ICIs atezolizumab (IMpower133), durvalumab (CASPIAN), or the PD-1 ICIs pembrolizumab (KEYNOTE-604) and nivolumab (ECOG-ACRIN EA5161). Besides the arms comparing chemotherapy alone or with durvalumab, CASPIAN trial included a third arm of chemotherapy + durvalumab + tremelimumab (CTLA-4 ICI). IMpower133 included a phase I part, representing a safety run-in period, followed by the phase III part of the study [22]. Disease responses were assessed according to RECIST version 1.1 in all the four trials.Standard chemotherapy in both standard and experimental arms included a platinum salt (either cisplatin or carboplatin, with the exception of IMpower133, where only carboplatin was allowed) administered on day 1 and etoposide administered on days 1-3, every three weeks. Slight differences between studies were recorded according to chemotherapy doses and the maximum number of cycles in the induction phase, as well as regarding the post-chemotherapy, maintenance phase with PD-1/PD-L1 ICIs (Table 1). Two studies were double-blind (IMpower133 and KEYNOTE-604) and two were open-label (CASPIAN and ECOG-ACRIN EA5161) with regard to PD-1/PD-L1 ICIs administration. 
Table 1. Characteristics of the trials included in the meta-analysis.

\begin{tabular}{|c|c|c|c|c|}
\hline Trial & IMpower133 & CASPIAN & KEYNOTE-604 & ECOG-ACRIN EA5161 \\
\hline Reference, update & $\begin{array}{c}\text { Horn New Engl J Med 2018 [22] } \\
\text { Reck ESMO } 2019 \text { [26] }\end{array}$ & $\begin{array}{l}\text { Paz-Ares Lancet } 2019 \text { [23] } \\
\text { Paz-Ares ASCO } 2020 \text { [27] }\end{array}$ & $\begin{array}{l}\text { Rudin J Clin Oncol } 2020 \text { [24] } \\
\text { Rudin ASCO } 2020 \text { [28] }\end{array}$ & Leal ASCO 2020 [29] \\
\hline Study phase & I-III & III & III & II \\
\hline Blinding & Double-blind & Open label & Double-blind & Open label \\
\hline Treatment Platinum salt & Carboplatin AUC5 & $\begin{array}{l}\text { Carboplatin AUC5-6 } \\
\text { Cisplatin } 75-80 \mathrm{mg} / \mathrm{m}^{2}\end{array}$ & $\begin{array}{l}\text { Carboplatin AUC5 } \\
\text { Cisplatin } 75 \mathrm{mg} / \mathrm{m}^{2}\end{array}$ & $\begin{array}{l}\text { Carboplatin AUC5-6 } \\
\text { Cisplatin } 75 \mathrm{mg} / \mathrm{m}^{2}\end{array}$ \\
\hline Treatment Etoposide & $100 \mathrm{mg} / \mathrm{m}^{2}$ & $80-100 \mathrm{mg} / \mathrm{m}^{2}$ & $100 \mathrm{mg} / \mathrm{m}^{2}$ & $100 \mathrm{mg} / \mathrm{m}^{2}$ \\
\hline Treatment Experimental arm & Atezolizumab $1200 \mathrm{mg}$ & Durvalumab $1500 \mathrm{mg}$ & Pembrolizumab $200 \mathrm{mg}$ & Nivolumab $360 \mathrm{mg}$ \\
\hline Treatment Control arm & Placebo & 1 & Placebo & 1 \\
\hline Treatment duration & $\begin{array}{c}4 \text { cycles chemo } \\
\text { Maintenance atezo/placebo }\end{array}$ & $\begin{array}{c}6 \text { cycles chemo arm } \\
4 \text { cycles combo }+ \text { maintenance } \\
\text { durva q4w }\end{array}$ & $\begin{array}{c}4 \text { cycles chemo } \\
\text { Maintenance atezo/placebo up } \\
\text { to } 35 \text { cycles }\end{array}$ & $\begin{array}{c}4 \text { cycles chemo } \\
4 \text { cycles combo }+ \text { maintenance } \\
\text { nivo } 240 \mathrm{mg} \mathrm{q} 2 \mathrm{w}\end{array}$ \\
\hline Primary endpoints & OS, PFS (IA) & OS & OS, PFS (BICR) & PFS \\
\hline Randomized patients & 403 & 537 & 453 & 160 \\
\hline Recruitment & June 2016-July 2017 & March 2017-May 2018 & May 2017-June 2018 & May 2018-December 2018 \\
\hline Stratification factors & Sex, ECOG PS, brain mets & Type of platinum salt & $\begin{array}{c}\text { Type of platinum salt, EGOG PS, } \\
\text { LDH }\end{array}$ & Sex, LDH \\
\hline Median follow-up (months) & 22.9 & 25.1 & 21.6 & NA \\
\hline Median PFS experimental/standard arms (months) & $\begin{array}{l}5.2(4.4-5.6) \\
4.3(4.2-4.5)\end{array}$ & $\begin{array}{l}5.1(4.7-6.2) \\
5.4(4.8-6.2)\end{array}$ & $\begin{array}{l}4.8(4.3-5.4) \\
4.3(4.2-4.5)\end{array}$ & $\begin{array}{l}5.5 \\
4.6\end{array}$ \\
\hline Median OS experimental/standard arms (months) & $\begin{array}{c}12.3(10.8-15.8) \\
10.3(9.3-11.3)\end{array}$ & $\begin{array}{c}12.9(11.3-14.7) \\
10.5(9.3-11.2)\end{array}$ & $\begin{array}{c}10.8(9.2-12.9) \\
9.7(8.6-10.7)\end{array}$ & $\begin{array}{c}11.3 \\
8.5\end{array}$ \\
\hline
\end{tabular}

Data between parenthesis represent 95\% confidence intervals. AUC: Area under the curve; q4w: Every four weeks; q2w: Every two weeks; OS: Overall survival; PFS: progression-free survival; IA: Investigator-assessed; BICR: Blinded independent central review. ECOG PS: Eastern Cooperative Oncology Group performance status; PFS: Progression-free survival; OS: Overall survival; NA: Not available. 
The inclusion of patients with baseline brain metastases was allowed across all the trials, if clinically controlled and asymptomatic; in addition, two trials (IMpower133 and KEYNOTE-604) required brain metastases being treated with radiotherapy or equivalent before study enrolment. PCI was allowed, with the exception of the experimental arm of CASPIAN study; no information is available concerning its feasibility in ECOG-ACRIN EA5161. Thoracic radiation was explicitly not permitted only in IMpower133, while the continuation of trial treatment beyond radiological progression, in the case of clinical benefit, was openly admitted in all the three studies published in extenso.

An update of IMpower133 was dedicated to toxicity and quality of life outcomes [25]. Nevertheless, as it reported adverse events (AEs) occurring in induction and maintenance phases of treatment separately, the total number of patients experiencing AEs during the whole study period could not be calculated, so toxicity data were obtained from previous communications.

\subsection{Patients' Characteristics}

Overall, 1553 patients were enrolled in the four trials included in the meta-analysis (intention-to-treat, ITT, population for efficacy analysis), 777 (50\%) assigned to platinum-based chemotherapy + PD-1/PD-L1 ICIs, and 776 (50\%) assigned to platinum-based chemotherapy alone. Main characteristics of the enrolled patients are described in Table 2. Patients were enrolled between June 2016 and December 2018. Median age was 62-65 years, and all patients had an ECOG performance status of $0(n=492,31.7 \%)$ or $1(1061,68.3 \%)$. Male sex was predominant $(n=1000,64.4 \%)$. Data regarding the platinum salt administered at study inclusion was available only for the three trials published in extenso: out of 1393 patients, 1122 (80.5\%) and $271(19.5 \%)$ received carboplatin and cisplatin, respectively. The number of patients with brain metastases was reported again only in published studies: overall, 145 out of 1393 (10.4\%) patients had brain metastases at inclusion. Liver metastases were present in 548 out of 1393 patients (39.3\%). Patients' characteristics were well balanced between experimental and treatment arms (Table 2). The proportion of patients who received subsequent treatment lines was similar between the two arms, with slightly higher percentages in chemotherapy-only ones. 
Table 2. Patients' characteristics across trials and as gathered in the meta-analysis.

\begin{tabular}{|c|c|c|c|c|c|c|c|c|c|c|}
\hline \multirow{2}{*}{$\begin{array}{c}\text { Patients' } \\
\text { Characteristics }\end{array}$} & \multicolumn{2}{|c|}{ IMpower133 [22,26] } & \multicolumn{2}{|c|}{ CASPIAN [23,27] } & \multicolumn{2}{|c|}{ KEYNOTE-604 [24,28] } & \multicolumn{2}{|c|}{ ECOG-ACRIN EA5161 [29] } & \multicolumn{2}{|c|}{ Total } \\
\hline & $\begin{array}{l}\text { Experimental } \\
(n=201)(\%)\end{array}$ & $\begin{array}{c}\text { Control } \\
(n=202)(\%)\end{array}$ & $\begin{array}{l}\text { Experimental } \\
(n=268)(\%)\end{array}$ & $\begin{array}{c}\text { Control } \\
(n=269)(\%)\end{array}$ & $\begin{array}{l}\text { Experimental } \\
(n=228)(\%)\end{array}$ & $\begin{array}{c}\text { Control } \\
(n=225)(\%)\end{array}$ & $\begin{array}{l}\text { Experimental } \\
(n=80)(\%)\end{array}$ & $\begin{array}{c}\text { Control } \\
(n=80)(\%)\end{array}$ & $\begin{array}{l}\text { Experimental } \\
(n=777)(\%)\end{array}$ & $\begin{array}{c}\text { Control } \\
(n=776)(\%)\end{array}$ \\
\hline \multicolumn{11}{|l|}{ Sex } \\
\hline Male & $129(64.2)$ & $132(65.3)$ & $190(70.9)$ & $184(68.4)$ & $152(66.7)$ & $142(63.1)$ & $35(43.7)$ & $36(45)$ & $506(65.1)$ & $494(63.7)$ \\
\hline Female & $72(35.8)$ & $70(34.7)$ & $78(29.1)$ & $85(31.6)$ & $76(33.3)$ & $83(36.9)$ & $45(56.3)$ & $44(55)$ & $271(34.9)$ & $282(36.3)$ \\
\hline \multicolumn{11}{|l|}{ Age } \\
\hline$<65$ years & $111(55.2)$ & $106(52.5)$ & $167(62.3)$ & $157(58.4)$ & $115(50.4)$ & $101(44.9)$ & NA & NA & $393(56.4)^{*}$ & $364(52.3)^{*}$ \\
\hline$\geq 65$ years & $90(44.8)$ & $96(47.5)$ & $101(37.7)$ & $112(41.6)$ & $113(50.6)$ & $124(55.1)$ & NA & NA & $304(43.6)^{*}$ & $332(47.7) *$ \\
\hline \multicolumn{11}{|l|}{ ECOG PS } \\
\hline 0 & $73(36.3)$ & $67(33.2)$ & $99(36.9)$ & $90(33.5)$ & $60(26.3)$ & $56(24.9)$ & $23(28.7)$ & $24(30)$ & $255(32.8)$ & $237(30.5)$ \\
\hline 1 & $128(63.7)$ & $135(66.8)$ & $169(63.1)$ & $179(66.5)$ & $168(73.7)$ & $169(75.1)$ & $57(71.3)$ & $56(70)$ & $522(67.2)$ & 539 (69.5) \\
\hline \multicolumn{11}{|l|}{ Platinum salt } \\
\hline Carboplatin & $201(100)$ & $202(100)$ & $201(75)$ & $201(74.7)$ & $161(70.6)$ & $156(69.3)$ & NA & NA & $563(80.8)^{*}$ & $559(80.3)^{*}$ \\
\hline Cisplatin & 0 & 0 & $67(25)$ & $68(25.3)$ & $67(29.4)$ & 69 (30.7) & NA & NA & $134(19.2)^{*}$ & $137(19.7)^{*}$ \\
\hline \multicolumn{11}{|l|}{$\begin{array}{c}\text { Brain } \\
\text { metastases }\end{array}$} \\
\hline No & $184(91.5)$ & 184 (91.1) & 240 (89.6) & $242(90)$ & 195 (85.5) & $203(90.2)$ & NA & NA & $619(88.8)$ * & $629(90.4) *$ \\
\hline Yes & 17 (8.5) & $18(8.9)$ & $28(10.4)$ & $27(10)$ & $33(14.5)$ & $22(9.8)$ & NA & NA & $78(11.2)^{*}$ & $67(9.6) *$ \\
\hline \multicolumn{11}{|l|}{$\begin{array}{c}\text { Liver } \\
\text { metastases }\end{array}$} \\
\hline No & 124 (61.7) & $130(63.4)$ & $160(59.7)$ & 165 (61.3) & $133(58.3)$ & 133 (59.1) & NA & NA & $417(59.8)^{*}$ & $428(61.5)^{*}$ \\
\hline Yes & 77 (38.3) & 72 (35.6) & $108(40.3)$ & $104(38.7)$ & 95 (41.7) & $92(40.9)$ & NA & NA & $280(40.2)^{*}$ & $268(38.5)^{*}$ \\
\hline \multicolumn{11}{|l|}{$\begin{array}{l}\text { Smoking } \\
\text { status }\end{array}$} \\
\hline Current & $74(36.8)$ & $75(37.1)$ & $120(44.8)$ & $126(46.8)$ & 148 (64.9) & 133 (59.1) & NA & NA & $342(49.1)^{*}$ & $334(48.0)^{*}$ \\
\hline Former & 118 (58.7) & $124(61.4)$ & $126(47.0)$ & $128(47.6)$ & $72(31.6)$ & $84(37.3)$ & NA & NA & $316(45.3)^{*}$ & $336(48.3)^{*}$ \\
\hline Never & $9(4.5)$ & $3(1.5)$ & $22(8.2)$ & $15(5.6)$ & $8(3.5)$ & $8(3.6)$ & NA & NA & $39(5.6) *$ & $26(3.7) *$ \\
\hline
\end{tabular}

ECOG PS: Eastern Cooperative Oncology Group performance status. NA: Not avaliable. ${ }^{*}$ Percentages are obtained out of a total of $n=697$ and $n=696$ patients in experimental and control arms, respectively, as information was not available regarding ECOG-ACRIN EA5161 trial. 


\subsection{Overall Survival}

The addition of a PD-1/PD-L1 ICI to platinum-etoposide chemotherapy in patients with ES SCLC was associated with a statistically significant benefit in OS in the whole study ITT population ( $n=1553$ ), [hazard ratio (HR) $0.76,95 \%$ confidence interval (CI) $0.68-0.85, p<0.00001$ ) (Figure 1 ). There was no evidence of asymmetry at the funnel plot (Figure S2). There was no evidence of significant heterogeneity among the four trials $\left(p=0.89, I^{2}=0 \%\right)$. In control and experimental arms, median OS ranged from 8.5 to 10.5 months and from 10.8 to 12.9 months, respectively (Table 1 ). The inclusion in the sensitivity analysis of the CASPIAN trial arm evaluating durvalumab and tremelimumab addition to chemotherapy (Figure S3), did not modify the estimations in favor of experimental treatments towards better OS (HR 0.77, 95\% CI 0.69-0.86, $p<0.00001$ ).

\section{A. Overall survival}

\begin{tabular}{|c|c|c|c|c|c|c|c|c|c|}
\hline Study or Subgroup & log[Hazard Ratio] & \multicolumn{2}{|r|}{$\mathrm{ICI}+$ chemotherapy } & \multicolumn{2}{|c|}{ Chemotherapy } & $\begin{array}{l}\text { Hazard Ratio } \\
\text { IV, Fixed, } 95 \% \mathrm{CI}\end{array}$ & \multicolumn{3}{|c|}{$\begin{array}{l}\text { Hazard Ratio } \\
\text { IV, Fixed, } 95 \% \mathrm{CI}\end{array}$} \\
\hline IMpower 133 & -0.2758 & 0.1165 & 201 & 202 & $25.2 \%$ & $0.76[0.60,0.95]$ & & & \\
\hline CASPIAN & -0.2877 & 0.0971 & 268 & 269 & $36.3 \%$ & $0.75[0.62,0.91]$ & & $-\square$ & \\
\hline KEYNOTE-604 & -0.2282 & 0.1081 & 228 & 225 & $29.3 \%$ & $0.80[0.64,0.98]$ & & $\rightarrow$ & \\
\hline ECOG-ACRIN EA5161 & -0.4005 & 0.1919 & 80 & 80 & $9.3 \%$ & $0.67[0.46,0.98]$ & & & \\
\hline Total $(95 \% \mathrm{Cl})$ & & & 777 & 776 & $100.0 \%$ & $0.76[0.68,0.85]$ & & & \\
\hline $\begin{array}{l}\text { Heterogeneity: } \mathrm{Chi}^{2}=0 \text {. } \\
\text { Test for overall effect: }\end{array}$ & $\begin{array}{l}3, d f=3(P=0.89) ; I^{2} \\
4.75(P<0.00001)\end{array}$ & & & & & & $\begin{array}{c}0.5 \\
\text { Favours |Cl+ }\end{array}$ & $\begin{array}{c}0.7 \\
\text { tchemotherapy }\end{array}$ & $\begin{array}{ccc}1 & 1.5 & 2 \\
\text { Favours chemotherapy }\end{array}$ \\
\hline
\end{tabular}

\section{B. Progression-free survival}

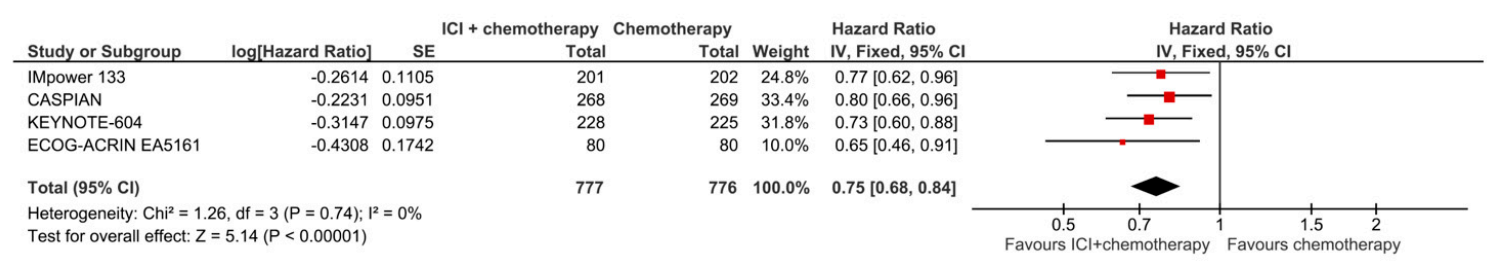

Figure 1. Overall survival (A) and progression-free survival (B) plots for the four clinical trials included in the meta-analysis, in the intention-to-treat populations. IV: Inverse variance; 95\% CI: 95\% confidence interval.

Landmark OS analyses at 12 and 18 months were available for three trials (IMpower133, CASPIAN and KEYNOTE-604), while CASPIAN and KEYNOTE-604 reported OS rates at 24 months. The 12-months OS rate in the control arms was $39-40 \%$ in the three studies, and was comprised from $45.1 \%$ to $52.8 \%$ in the experimental arms; 18 -months OS rate rates ranged from $21 \%$ to $24.8 \%$ and from $30 \%$ to $34 \%$, respectively. At 24-months, OS rate in control arms of CASPIAN and KEYNOTE-604 were respectively $14.4 \%$ and $11.2 \%$, rising to $22 \%$ in the immunotherapy-containing regimens in both studies. Pooled analysis of the probability of being alive at the mentioned landmark time points is reported in Table 3. For all the three time-points mentioned, the probability to be alive was significantly in favor of the experimental arms, with a delta of $+10.9 \%(95 \% \mathrm{CI}$ from $+5.6 \%$ to $+16.1 \%, p=0.0001)$ at 12 months, $+9.4 \%(95 \% \mathrm{CI}$ from $+4.5 \%$ to $+14.1 \%, p=0.0002)$ at 18 months and $+8.7 \%(95 \% \mathrm{CI}$ from $+1.8 \%$ to $+15.4 \%, p=0.013)$ at 24 months.

In subgroup analyses (Figure 2), based on the data of the three trials published in extenso, the test for difference of treatment efficacy among the subgroups did not demonstrate a statistically significant interaction. 
Table 3. Pooled landmark analyses for OS and PFS.

\begin{tabular}{|c|c|c|c|c|c|c|c|c|c|}
\hline \multirow{2}{*}{$\begin{array}{c}\text { Landmark } \\
\text { Survival Analyses }\end{array}$} & \multicolumn{3}{|c|}{ Control Arm } & \multicolumn{3}{|c|}{ Experimental Arm } & \multicolumn{3}{|c|}{ Delta } \\
\hline & Patients at risk & Probability & $95 \% \mathrm{CI}$ & Patients at risk & Probability & $95 \% \mathrm{CI}$ & $\%$ & $95 \%$ CI & $p$ value \\
\hline 12-months OS (3 trials) [26-28] & 267 & 0.3932 & $0.3564-0.4312$ & 335 & 0.5021 & $0.4634-0.5408$ & $10.89 \%$ & $5.58-16.11 \%$ & 0.0001 \\
\hline 18 -months OS ( 3 trials) [26-28] & 147 & 0.2265 & $0.1956-0.2615$ & 206 & 0.3201 & $0.2847-0.3582$ & $9.36 \%$ & $4.50-14.16 \%$ & 0.0002 \\
\hline 24-months OS (2 trials) $[27,28]$ & 32 & 0.136 & $0.0963-0.1883$ & 56 & 0.2228 & $0.1742-0.2807$ & $8.68 \%$ & $1.83-15.40 \%$ & 0.0131 \\
\hline 6-months PFS (3 trials) [26-28] & 210 & 0.3508 & $0.3132-0.3911$ & 253 & 0.3865 & $0.3496-0.4256$ & $3.57 \%$ & $-1.78-8.88 \%$ & 0.1916 \\
\hline 12-months PFS (3 trials) [26-28] & 32 & 0.0523 & $0.0366-0.0738$ & 98 & 0.1611 & $0.1334-0.1934$ & $10.89 \%$ & $7.48-14.36 \%$ & $<0.0001$ \\
\hline 18 -months PFS ( 2 trials) $[27,28]$ & 10 & 0.0301 & $0.0154-0.0564$ & 50 & 0.1297 & $0.0988-0.1686$ & $9.96 \%$ & $6.10-13.93 \%$ & $<0.0001$ \\
\hline
\end{tabular}

OS: Overall survival; PFS: Progression-free survival. 95\% CI: 95\% Confidence interval. 


\section{A. Platinum salt administered (cisplatin/carboplatin)}

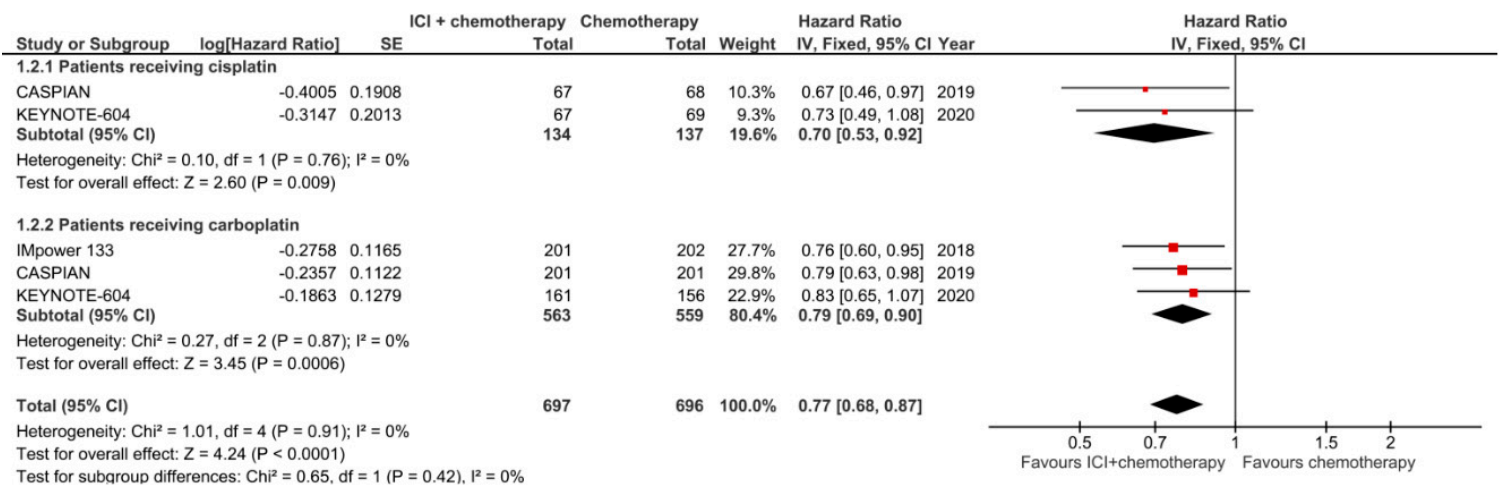

\section{B. Sex}

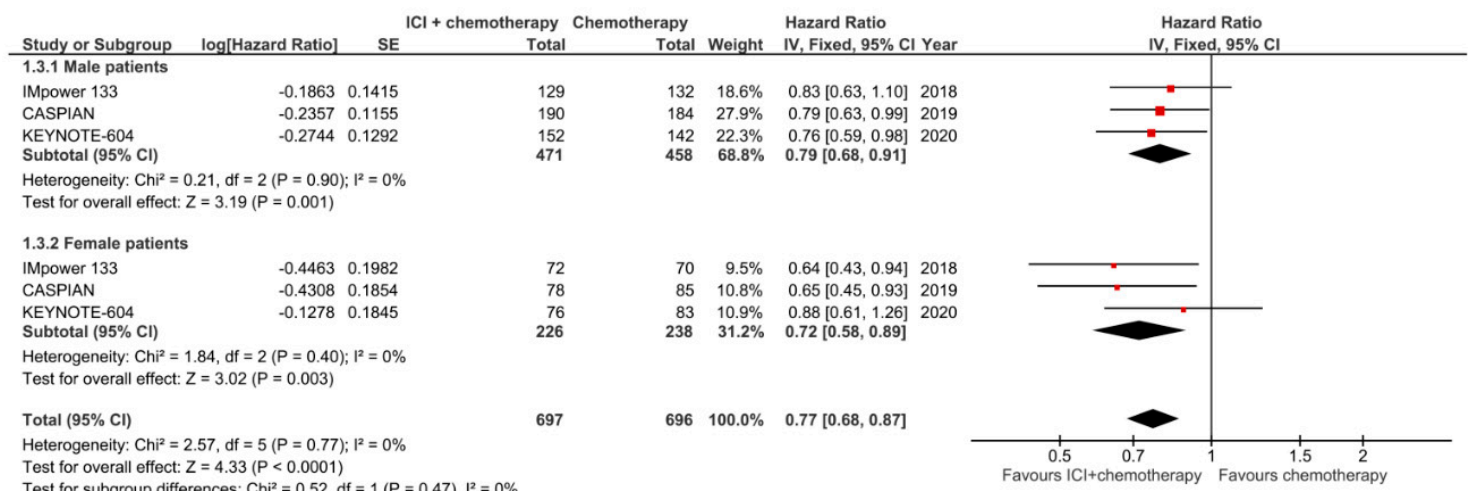

\section{Age $(<65$ years $/ \geq 65$ years $)$}

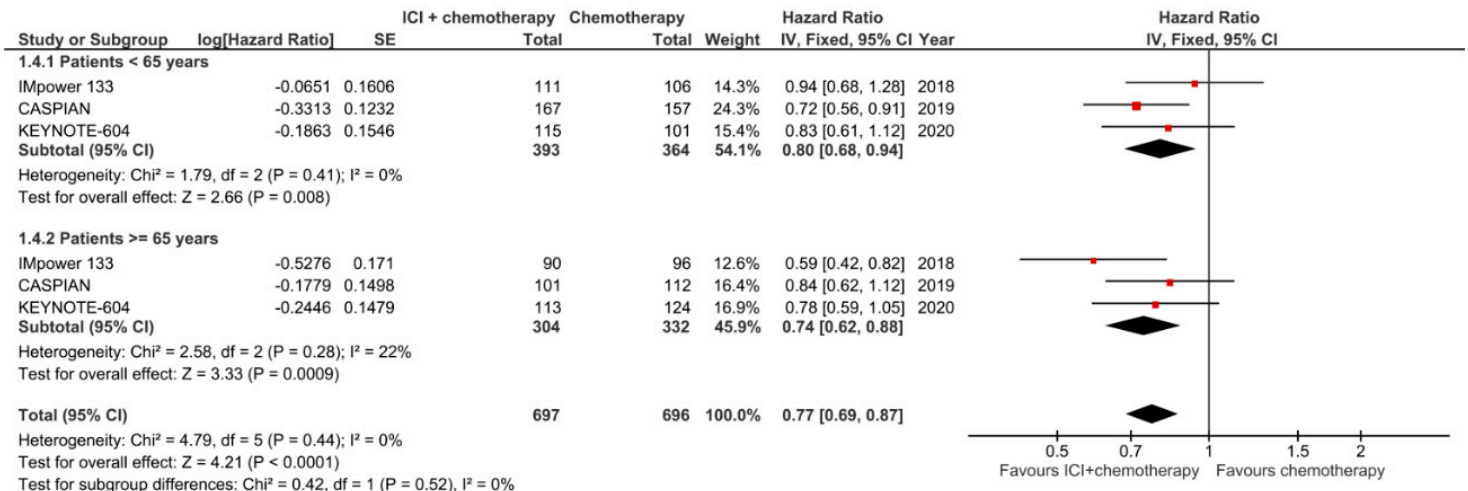

Figure 2. Cont. 


\section{ECOG performance status (0/1)}

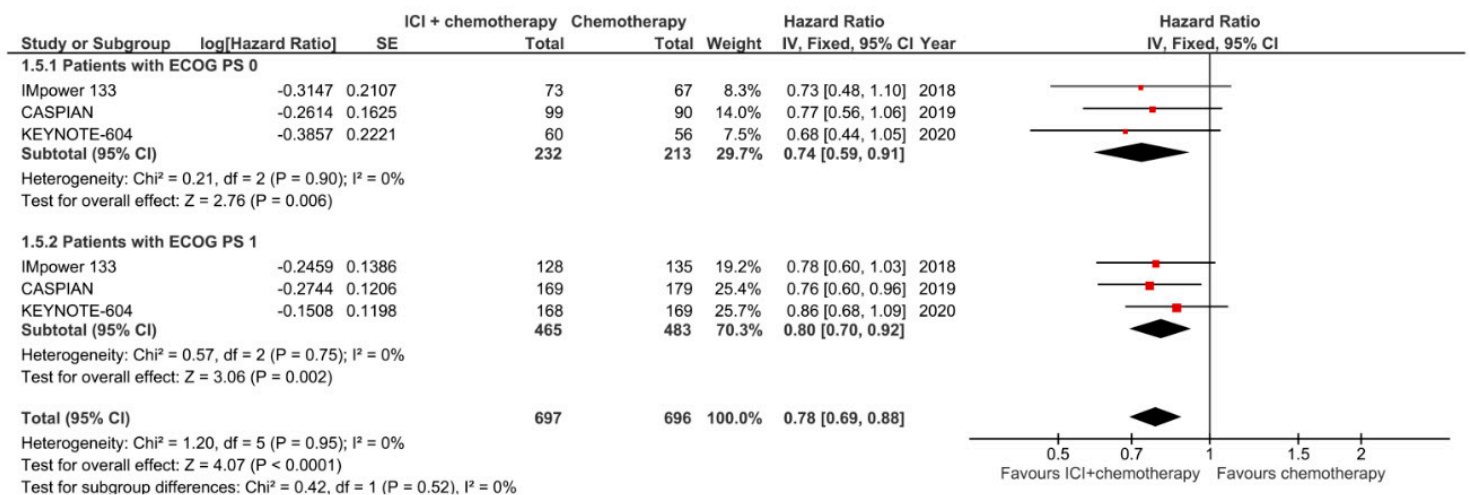

\section{E. Liver metastases (absent/present)}

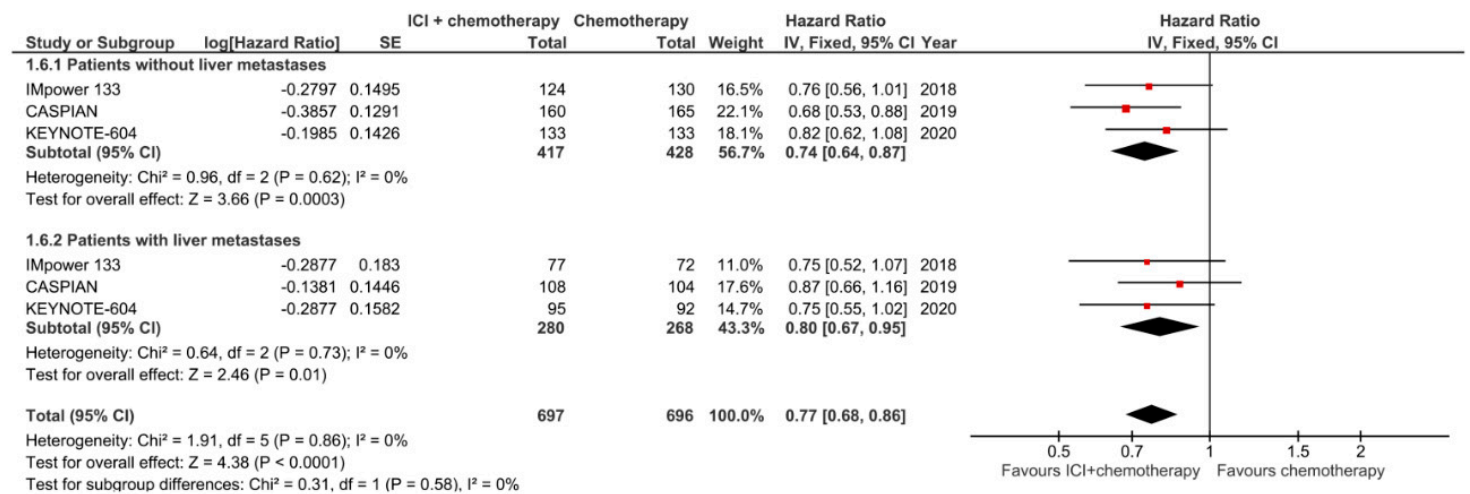

\section{F. Brain metastases (absent/present)}

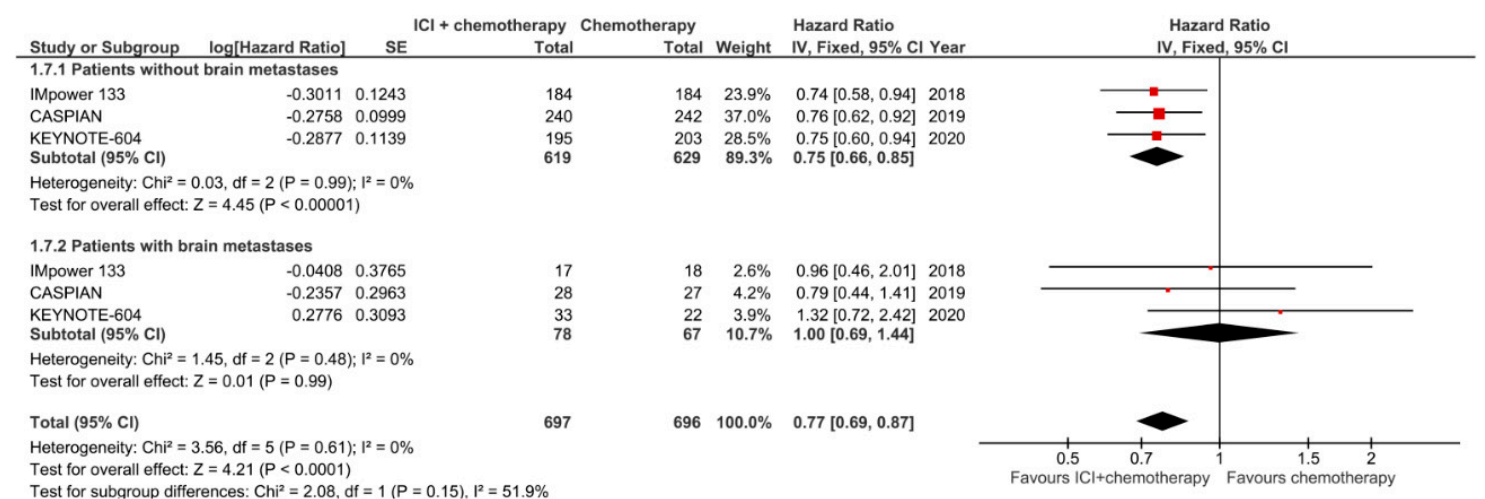

Figure 2. Overall survival. Subgroups analyses (A-F) for overall survival for the four clinical trials included in the meta-analysis, in the intention-to-treat populations. IV: Inverse variance; 95\% CI: 95\% confidence interval.

\subsection{Progression-Free Survival}

In the whole population ( $n=1553$, data available for all the four eligible trials), the addition of a PD-1/PD-L1 ICI to platinum-etoposide chemotherapy in patients with ES SCLC was associated with a statistically significant benefit in progression-free survival (HR 0.75, 95\% CI 0.68-0.84, $p<0.00001$ ) (Figure 1). There was no evidence of significant heterogeneity among the four trials $\left(p=0.74, I^{2}=0 \%\right)$. In control and experimental arms, median PFS ranged from 4.3 to 5.4 months and from 4.8 to 5.5 months, respectively (Table 1 ). 
Landmark PFS analyses at 6 and 12 months were available for three trials (IMpower133, CASPIAN and KEYNOTE-604), while CASPIAN and KEYNOTE-604 reported PFS rates at 18 months. The 6-months PFS rate ranged from $22.4 \%$ to $45.8 \%$ in control arms and from $30.9 \%$ to $45.4 \%$ in experimental ones. At 12 months, only 5\% of patients receiving chemotherapy only were progression-free across trials, while $12.6-17.9 \%$ had not progressed when a PD-1/PD-L1 ICI had been added to chemotherapy. At the 18-months landmark analysis, $2.1-3.4 \%$ and $10.8-13.9 \%$ of the patients in control and experimental arms, respectively, were still progression-free. Pooling PFS events (Table 3), PFS-rates at 12 and 18 months were significantly higher with PD-1/PD-L1 ICI addition to chemotherapy, with a delta of $+3.6 \%(95 \%$ CI from $-1.8 \%$ to $+8.9 \%, p=0.19)$ at 6 months, $+10.9 \%$ $(95 \% \mathrm{CI}$ from $+7.5 \%$ to $+14.4 \%, p<0.0001)$ at 12 months and $+10.0 \%(95 \% \mathrm{CI}$ from $+6.1 \%$ to $+13.9 \%$, $p<0.0001)$ at 18 months.

\subsection{Response Rate}

Objective responses observed across trials are recapitulated in Figure 3. In the whole study population ( $n=1553$, data available for the four trials), the addition of a PD-1/PD-L1 ICI to platinum-etoposide chemotherapy in patients with ES SCLC was associated with a statistically significant increase in ORR [odds ratio (OR) 1.28, 95\% CI 1.04-1.57, $p=0.02$ ] (Figure 3). In the whole study population ( $n=1553$, data available for the four trials), a statistically significant increase in ORR [odds ratio (OR) 1.28, 95\% CI 1.04-1.57, $p=0.02$ ] was observed when PD-1/PD-L1 ICIs were added to platinum-etoposide chemotherapy in patients with ES SCLC (Figure 3).

\section{A. Objective response rate}

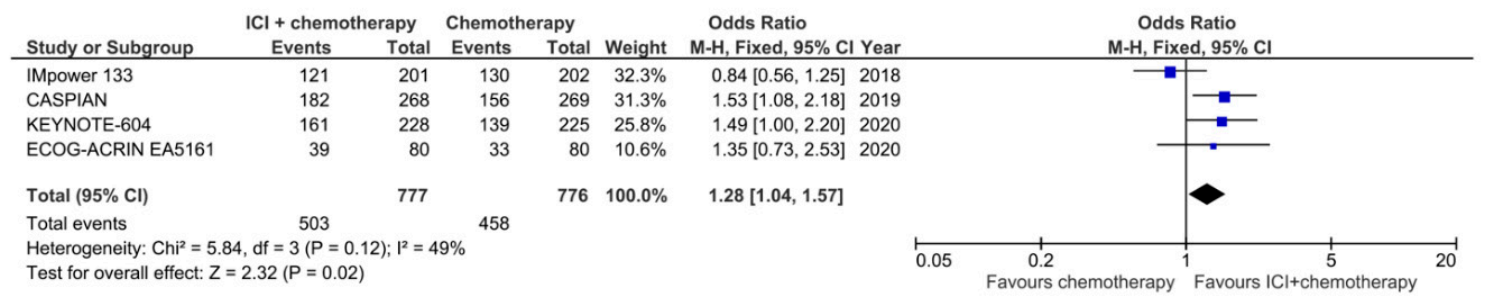

\section{B. Complete response rate}

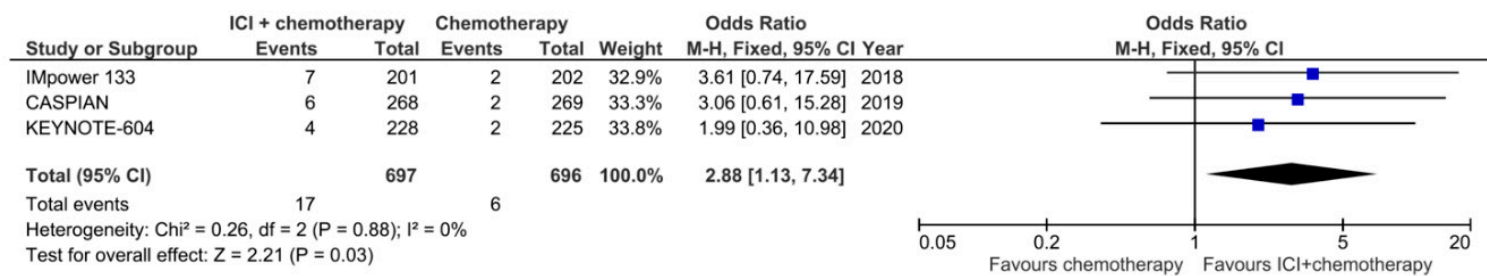

Figure 3. Objective response rate (A) and complete response rate (B) for the four clinical trials included in the meta-analysis, in the intention-to-treat populations. M-H: Mantel-Haenszel; 95\% CI: 95\% confidence interval.

Overall, ORR was equal to $59.0 \%$ (458/776) in the control arm vs. 64.7\% (503/777) in the experimental arm. Response rates were higher in experimental arms in all trials but IMpower133, and there was a moderate, non-significant heterogeneity among trials $\left(I^{2}=49 \%, p=0.12\right)$.

Focusing on complete responses (available in three trials), although uncommon, they too were obtained more frequently in experimental $(2.4 \%)$ compared to standard treatment arms $(0.9 \%)$ (Figure 3$)$. 


\subsection{Toxicity}

As expected, the addition of PD-1/PD-L1 ICs was accompanied with a numerical increase of AEs recorded through the three trials published in extenso (only grade 5, G5, treatment-related events could be extrapolated from ECOG-ACRIN EA5161) (Figure S4). Pooling patients having experienced AEs (Table 4), all-grade toxicities were more common in the experimental arms (OR 2.89, 95\% CI 1.13-7.38, $p=0.03$ ), while no significant difference was observed with regard to G3-4 events (OR $1.08,95 \% \mathrm{CI}$ $0.86-1.36, p=0.51)$. Toxicities leading to the withdrawal of any treatment component were more common when PD-1/PD-L1 ICs were added to chemotherapy (OR 1.98, 95\% CI1.36-2.89, $p=0.0004$ ). No difference in G5 AEs emerged (Table 4).

Table 4. Pooled analysis of toxicity data in the safety population of control and experimental arms.

\begin{tabular}{|c|c|c|c|c|c|c|}
\hline Adverse Events & $\begin{array}{l}\text { Control Arm } \\
\text { Events/Patients }\end{array}$ & $\%$ & $\begin{array}{l}\text { Experimental Arm } \\
\text { Events/Patients }\end{array}$ & $\%$ & Odds Ratio (95\% CI) & $p$ Value \\
\hline All adverse events & $669 / 685$ & 97.7 & $681 / 686$ & 99.3 & $2.89(1.13-7.38)$ & 0.03 \\
\hline $\begin{array}{l}\text { AE leading to withdrawal of any } \\
\text { treatment component }\end{array}$ & $45 / 685$ & 6.6 & $84 / 685$ & 12.3 & $1.98(1.36-2.89)$ & 0.0004 \\
\hline Grade 5 adverse events & $12 / 755$ & 1.6 & $16 / 761$ & 2.1 & $1.33(0.63-2.84)$ & 0.46 \\
\hline Dermatitis/rash, grade 3-4 & $0 / 685$ & 0 & $7 / 686$ & 1.0 & $8.09(1.01-64.99)$ & 0.05 \\
\hline Hepatitis, all grades & $9 / 685$ & 1.3 & $26 / 686$ & 3.8 & $2.81(1.34-5.90)$ & 0.006 \\
\hline Hepatitis, grade $3-4$ & $0 / 685$ & 0 & $11 / 686$ & 1.6 & $8.45(1.55-46.12)$ & 0.01 \\
\hline Hypothyroidism, all grades & $8 / 685$ & 1.7 & $72 / 686$ & 10.5 & $9.90(4.73-20.73)$ & $<0.00001$ \\
\hline Hypothyroidism, grade 3-4 & $0 / 685$ & 0 & $0 / 686$ & 0 & NA & - \\
\hline Hyperthyroidism, all grades & $11 / 685$ & 1.6 & $40 / 686$ & 5.8 & $3.68(1.89-7.15)$ & 0.0001 \\
\hline Colitis, grade $3-4$ & $2 / 685$ & 0.3 & $4 / 686$ & 0.6 & $1.67(0.40-7.00)$ & 0.49 \\
\hline Adrenal insufficiency, all grades & $4 / 685$ & 0.6 & $3 / 686$ & 0.4 & $0.80(0.21-2.97)$ & 0.73 \\
\hline Adrenal insufficiency, grade 3-4 & $0 / 685$ & 0 & $2 / 686$ & 0.3 & $5.05(0.24-105.69)$ & 0.30 \\
\hline Type I diabetes, all grades & $0 / 685$ & 0 & $6 / 686$ & 0.9 & $5.04(0.87-29.13)$ & 0.07 \\
\hline Type I diabetes, grade 3-4 & $0 / 685$ & 0 & $5 / 686$ & 0.7 & $6.07(0.73-50.57)$ & 0.10 \\
\hline
\end{tabular}

G3-4 irAEs were rare, never exceeding 1\%. AEs: Adverse events; 95\% CI: 95\% confidence interval.

Focusing on immune-related AEs (irAEs), as expected they were more common in experimental arm (OR 3.18, 95\% CI 2.35-4.29, $p<0.00001)$. When PD-1/PD-L1 ICIs were added to chemotherapy, the most frequently observed irAE, were dermatitis/rash (10.8\%) and thyroid dysfunctions $(16.3 \%)$.

\section{Discussion}

Biological and clinical disease aggressiveness, as well as the lack of active treatment options, are the major responsible for the dismal survival outcomes of ES SCLC patients. Compared to the recent improvements in NSCLC management, the standard of care of SCLC has not been significantly modified since its establishment approximately 30 years ago. The results observed with ICIs in NSCLC since their introduction, from the advanced pre-treated setting to the earlier ones, are outstanding. Still with a less impressive magnitude of benefit, the combination of PD-1/PD-L1 ICIs to backbone first-line chemotherapy has a significant impact on all the observed outcomes, as shown in this meta-analysis.

Among the four trials adding PD-1/PD-L1 ICIs to platinum-etoposide therapy in ES SCLC, three were positive, satisfying their respective primary outcomes. Only KEYNOTE-604 (sharing independently-assessed PFS and OS as primary endpoints) resulted formally negative, as the improvement in OS obtained in the experimental arm containing pembrolizumab (HR 0.80, 95\% $0.64-0.98, p=0.0164$ ) did not reach the established significance boundary of $p=0.0128$ [24]. Albeit considered a secondary endpoint, OS was superior in the nivolumab arm of ECOG-ACRIN EA5161, compared to the chemotherapy-only one [29]. In all the trials, PFS was superior in the experimental compared to the standard treatment arms. 
The difference in median OS between standard and PD-1/PD-L1 ICI containing regimes ranged from 1.1 (KEYNOTE-604) to 2.8 (ECOG-ACRIN EA5161) months. The limited value of median estimations in assessing survival benefit in this setting is even more represented by the difference in median PFS, numerically favoring control arm (0.3 months) in CASPIAN and up to 0.9 months in favor of experimental regimens in IMpower133 and ECOG-ACRIN EA5161. As often observed in clinical trials evaluating ICIs in solid tumors, the improvements in survival outcomes can be more evident if looking at the tales of Kaplan-Meyer curves [30]. Indeed, when pooling the events of the published studies focusing on landmark analyses, the probability of being alive at 12, 18 and 24 months since treatment initiation in experimental arms was 50.2\%, 32.0\% and $22.3 \%$ respectively, exceeding of approximately $10 \%$ the corresponding rates in standard treatment (Table 3 ). With the exception of the 6-months timepoint (likely due to its early assessment), similar deltas between experimental and standard treatment arms were observed for PFS rates at 12 and 18 months (Table 3). A key element for clinical decision and for the future development of ICIs in this setting will be the definition of biomarkers predicting the patients suitable for long-term benefit. Thus far, PD-L1 has failed in this purpose and TMB evaluation, potentially linked to ICIs benefit when administered in pre-treated SCLC in retrospective evaluations [31,32], did not show predictive value in IMpower133 [24,26]. The recognition of diverse biological entities within SCLC, responsible for differential clinical behaviors and response to therapies, represent the most promising way to identify patients more likely to benefit from immunotherapy options [33].

Dealing with toxicity, irAEs occurring when PD-1/PD-L1 ICIs were added to chemotherapy had a mild impact on the overall toxicity, only slightly higher in the experimental arm (Table 4). No difference was recorded with regard to G3-4 AEs. Serious irAEs were observed in a minority of patients only, thus scaling down the putative risk of unleashing uncontrolled, previously subclinical autoimmune paraneoplastic syndromes, as seen with thymic malignancies [34].

Envisaging the translation of the observed results in the clinical practice, two major elements seem worthy of being mentioned. First, described trials only included ECOG PS 0-1 patients. Due to both comorbidities and disease burden nevertheless, ES SCLC patients present with poor PS at diagnosis in up to $30 \%$ of the cases [35-37]. Even lacking clear evidence of adding PD-1/PD-L1 agents to chemotherapy in ECOG PS 2-3 ES SCLC patients, this clinical behavior could anyway provide clinical benefit, as clinical improvements are usually rapidly observed after cytotoxic treatment onset, and immunotherapy (besides increasing the response rates, as seen), could therefore exert its effect on the medium-long term. Second, the inclusion of patients with brain metastases was allowed, but only in the case of their clinical stability and, in IMpower133 and KEYNOTE-604, before having been treated with radiotherapy. This is likely the reason why a smaller proportion of patients harbored brain disease in these clinical trials (10.4\% overall, Table 2) compared to clinical practice (up to $24 \%$ ) [38]. In daily routine moreover, patients with brain metastases are usually candidate to receive upfront chemotherapy (delaying radiotherapy), due to the good responses obtained by systemic therapy even at the intracranial level. Given the potentially detrimental effect of steroids on the activity of immunotherapy [39], patients undergoing high-dose steroids for symptomatic brain metastases could potentially initiate chemotherapy only, introducing PD-1/PD-L1 agents in case of intracranial disease response and steroids tapering.

It could be argued that the patients who drive the largest benefits from immunotherapy addition are the same who could take advantage of their administration in the third or later treatment line $[20,21]$. This hypothesis represents speculation yet to be acknowledged, and moving PD-1/PD-L1 agents upfront may guarantee the full exertion of their synergy with chemotherapy. In addition, this strategy allows all the patients to be exposed to immunotherapy when they are still reasonably fit, as the recalcitrant and aggressive clinical behavior of SCLC progressively reduces patients receiving second and later treatment lines.

We recognize that a meta-analysis based on individual patient data (IPD) should be considered the optimal synthesis of evidence, because it could allow data verification, the potential update of 
follow-up compared to data reported in publications, better calculation and comparison of time to events, and more accurate study of treatment heterogeneity in patients' subgroups [40]. However, considering that data of the eligible trials included in our systematic review are property of different sponsors (and that it is highly unlikely that all those data could be rapidly obtained and analyzed together), the present meta-analysis based on literature-based data has allowed a timely synthesis of the evidence available, and could be considered an acceptable surrogate of IPD meta-analysis.

\section{Materials and Methods}

\subsection{Evidence Acquisition}

\subsubsection{Identification of Eligible Trials and Evaluation of Study Quality}

A search was performed in June 2020, to identify all randomized trials (both phase II and phase III) testing the addition of a single anti-PD-1 or anti-PD-L1 ICIs to first-line platinum-based chemotherapy in patients with ES SCLC. The literature search was performed using PubMed. The following key-words were used for the search: (small cell lung cancer) AND (nivolumab OR pembrolizumab OR atezolizumab OR avelumab OR durvalumab) AND (random*). In addition, references of the identified articles were checked to identify further eligible trials. Furthermore, proceedings of the main International meetings [American Society of Clinical Oncology (ASCO) annual meeting, European Society of Medical Oncology (ESMO]) annual meeting, International Association for the Study of Lung Cancer (IASLC) World Conference on Lung Cancer], were searched from 2017 onwards for relevant abstracts.

When more than one analysis was available for the same clinical trial, we included in the analysis the most recent information (corresponding to longer follow-up).

All the eligible trials were assessed for study quality and potential bias using a structured checklist based on the Method for Evaluating Research and Guideline Evidence (MERGE) criteria. In detail, the checklist considers the quality of randomization, blinding, outcome measures, measure assessment, arm comparability, loss to follow-up, and intention to treat analysis. This checklist allows to assign a quality score to each trial: A (low risk of bias), B1 (low to moderate risk of bias), B2 (moderate to high risk of bias), $\mathrm{C}$ (high risk of bias).

\subsubsection{Data Collection}

We performed a meta-analysis aggregating data obtained from study publications.

For each eligible trial, the following data were collected, if available:

- main inclusion criteria: patients' age, ECOG performance status (PS), disease stage;

- details of treatment on study: platinum-based chemotherapy (drugs, doses and number of cycles), immune checkpoint inhibitor (drug, dose and duration of treatment);

- clinical trial methodology: primary endpoint, study hypothesis;

- patients' accrual and follow-up: the date of start and date of the end of accrual; number of patients randomized to experimental arm, number of patients randomized to control arm, median follow-up;

- OS: number of deaths in each arm, median OS, HR with $95 \% \mathrm{CI}, p$-value; for each arm, probability of being alive at 12 months, 18 months, 24 months from randomization. Details (number of patients and deaths in each arm, HR with $95 \% \mathrm{CI}$ ) were collected also for selected subgroups: age $(<65 y / \geq 65 y)$, sex (males/females), ECOG PS (0/1), liver metastases (present/absent), brain metastases (present/absent), type of platinum administered (cisplatin/carboplatin).

- PFS: number of events in each arm, median PFS HR with 95\% CI, $p$-value; for each arm, probability of being progression-free at 6 months, 12 months, 18 months from randomization.

- ORR and complete response rate: number of events in each arm.

- Toxicity: number of events of all-grades and G3-4 AEs; irAEs; AEs leading to the withdrawal of any treatment; G5 AEs; all-grades and G3-4 organ-specific irAEs. 


\subsubsection{Statistical Methods}

After data were abstracted, the analysis was performed with the Review Manager (RevMan (Computer program). Version 5.3. Copenhagen: The Nordic Cochrane Centre, The Cochrane Collaboration, 2014.) software. For all the trials included in the meta-analysis, efficacy (OS) and activity (PFS, ORR, complete response rate) were analyzed from all randomly assigned patients on an ITT basis.

For both OS and PFS, the summary measure was the hazard ratio (with 95\% CI). For response rate and toxicity, the summary measure was the odds ratio (with 95\% CI). A fixed-effects model was applied, and all analyses were repeated also with a random-effects model to verify consistency. Statistical heterogeneity among the included studies was examined using the $\chi^{2}$ test and the $\mathrm{I}^{2}$ statistic. The latter statistic expresses the proportion of the total observed variability attributed to study heterogeneity. In order to assess publication bias, although its reliability is limited due to the low number of included studies, we examined funnel plot, with standard error of the log (Hazard Ratio) on the y-axis and the Hazard Ratio on the $x$-axis.

In one trial [23,27], a further experimental arm was reported, testing the addition of durvalumab and tremelimumab to chemotherapy. Although all the other comparisons included in the main analysis tested the addition of single-agent ICIs, we performed an exploratory analysis also adding this comparison. However, because that trial used the same control arm for both comparisons (durvalumab + chemotherapy vs. chemotherapy alone, and durvalumab + tremelimumab + chemotherapy vs. chemotherapy alone), the weight of each comparison was reduced according to a correction factor equal to the number of events actually observed in the trial, divided by the number of events taken into account in the analysis (where the control arm was counted twice). For both comparisons, this correction produced a prudential increase in the width of the CI for the estimated HR.

Subgroup analyses were performed testing the heterogeneity of treatment effect among subgroups, using an interaction test.

For the calculation of the pooled probability of being event-free at prespecified time points (12, 18 and 24 months for OS; 6, 12 and 18 months for PFS), only trials displaying numbers of patients at risk at each defined landmark time were included in the pooled population; when not available, the probability of being event-free for each specific time points was inferred, with approximation, from Kaplan-Meier survival curves.

Given the unavailability of standard errors/confidence intervals for the probability, in the pooled calculation the probability reported in each trial was weighted by the number of patients at risk. At each time point, the difference in probability between treatment arms, the confidence interval and the statistical significance were calculated using MedCalc [41].

\section{Conclusions}

In this meta-analysis, the addition of PD-1/PD-L1 ICIs to backbone platinum-etoposide chemotherapy in the first-line treatment of ES SCLC has been shown to be active, effective, and safe. Albeit the magnitude of the effect may be deemed relative if compared to other settings and other diseases (namely NSCLC), the OS survival rates at 12-, 18-, and 24-months $(50.2 \%, 32.0 \%, 22.3 \%$, respectively) sustain the introduction of these regimens in the standard of care of ES SCLC patients. Further steps in the comprehension of SCLC biology will hopefully shed light on which patients derive the largest benefits from chemo-immunotherapy combinations [42]. After decades, these latter represent the novel standard of care for the treatment of ES SCLC and should be considered the benchmark for the development of even better treatment strategies.

Supplementary Materials: The following are available online at http://www.mdpi.com/2072-6694/12/9/2645/s1, Figure S1: PRISMA flow diagram depicting the systematic review process leading to the identification of studies included in the meta-analysis, Figure S2: Funnel plot for overall survival, Figure S3: Overall survival plots considering CASPIAN arm with chemotherapy + durvalumab + tremelimumab, Figure S4: Adverse events recorded in the four trials included in the meta-analysis, in the safety populations. 
Author Contributions: Conceptualization, All Authors; Methodology M.D.M.; Formal Analysis, All Authors; Data Curation, F.F. and M.D.M.; Writing-Original Draft Preparation, F.F.; Writing-Review \& Editing, M.D.M. and M.T.; Supervision, M.D.M. and M.T. All authors have read and agreed to the published version of the manuscript.

Funding: There was no funding source for this systematic review and meta-analysis. All authors had full access to all the data and the corresponding author (Massimo Di Maio, medical oncologist with a long-standing experience in clinical trial methodology and in meta-analyses) had final responsibility for the decision to submit for publication.

Acknowledgments: Marcello Tiso is currently supported by the Associazione Italiana per la Ricerca sul Cancro (AIRC) under Investigator Grant (IG) No. IG2017-20074.

Conflicts of Interest: Francesco Facchinetti has participated to editorial activities sponsored by BMS and Roche. Massimo Di Maio received advisory board or consultant fees from Merck Sharp \& Dohme, Bristol Myers Squibb, Eisai, Janssen, Astellas, AstraZeneca, Pfizer, Takeda and institutional research grant from Tesaro-GSK. Marcello Tiseo received speakers' and consultants' fee from Astra-Zeneca, Pfizer, Eli-Lilly, BMS, Novartis, Roche, MSD, Boehringer Ingelheim, Otsuka, Takeda, Pierre Fabre. M.T. received institutional research grants from Astra-Zeneca, Boehringer Ingelheim.

\section{References}

1. Govindan, R.; Page, N.; Morgensztern, D.; Read, W.; Tierney, R.; Vlahiotis, A.; Spitznagel, E.L.; Piccirillo, J. Changing epidemiology of small-cell lung cancer in the United States over the last 30 years: Analysis of the surveillance, epidemiologic, and end results database. J. Clin. Oncol. 2006, 24, 4539-4544. [CrossRef] [PubMed]

2. Van Meerbeeck, J.P.; Fennell, D.A.; De Ruysscher, D.K.M. Small-cell lung cancer. Lancet 2011, 378, 1741-1755. [CrossRef]

3. Rossi, A.; Di Maio, M.; Chiodini, P.; Rudd, R.M.; Okamoto, H.; Skarlos, D.V.; Früh, M.; Qian, W.; Tamura, T.; Samantas, E.; et al. Carboplatin- or cisplatin-based chemotherapy in first-line treatment of small-cell lung cancer: The COCIS meta-analysis of individual patient data. J. Clin. Oncol. 2012, 30, 1692-1698. [CrossRef] [PubMed]

4. Von Pawel, J.; Schiller, J.H.; Shepherd, F.A.; Fields, S.Z.; Kleisbauer, J.P.; Chrysson, N.G.; Stewart, D.J.; Clark, P.I.; Palmer, M.C.; Depierre, A.; et al. Topotecan versus cyclophosphamide, doxorubicin, and vincristine for the treatment of recurrent small-cell lung cancer. J. Clin. Oncol. 1999, 17, 658-667. [CrossRef] [PubMed]

5. Eckardt, J.R.; Von Pawel, J.; Pujol, J.L.; Papai, Z.; Quoix, E.; Ardizzoni, A.; Poulin, R.; Preston, A.J.; Dane, G.; Ross, G. Phase III study of oral compared with intravenous topotecan as second-line therapy in small-cell lung cancer. J. Clin. Oncol. 2007, 25, 2086-2092. [CrossRef]

6. Owonikoko, T.K.; Behera, M.; Chen, Z.; Bhimani, C.; Curran, W.J.; Khuri, F.R.; Ramalingam, S.S. A systematic analysis of efficacy of second-line chemotherapy in sensitive and refractory small-cell lung cancer. J. Thorac. Oncol. 2012, 7, 866-872. [CrossRef]

7. Maeng, C.H.; Song, J.U.; Shim, S.R.; Lee, J. The Role of Prophylactic Cranial Irradiation in Patients With Extensive Stage Small Cell Lung Cancer: A Systematic Review and Meta-Analysis. J. Thorac. Oncol. 2018, 13, 840-848. [CrossRef]

8. Rathod, S.; Jeremic, B.; Dubey, A.; Giuliani, M.; Bashir, B.; Chowdhury, A.; Liang, Y.; Pereira, S.; Agarwal, J.P.; Koul, R. Role of thoracic consolidation radiation in extensive stage small cell lung cancer: A systematic review and meta-analysis of randomised controlled trials. Eur. J. Cancer 2019, 110, 110-119. [CrossRef]

9. Rossi, A.; Garassino, M.C.; Cinquini, M.; Sburlati, P.; Di Maio, M.; Farina, G.; Gridelli, C.; Torri, V. Maintenance or consolidation therapy in small-cell lung cancer: A systematic review and meta-analysis. Lung Cancer 2010, 70, 119-128. [CrossRef]

10. Tiseo, M.; Boni, L.; Ambrosio, F.; Camerini, A.; Baldini, E.; Cinieri, S.; Brighenti, M.; Zanelli, F.; Defraia, E.; Chiari, R.; et al. Italian, multicenter, phase III, randomized study of cisplatin plus etoposide with or without bevacizumab as first-line treatment in extensive-disease small-cell lung cancer: The GOIRC-AIFA FARM6PMFJM trial. J. Clin. Oncol. 2017, 35, 1281-1287. [CrossRef]

11. Schultheis, A.M.; Scheel, A.H.; Ozretić, L.; George, J.; Thomas, R.K.; Hagemann, T.; Zander, T.; Wolf, J.; Buettner, R. PD-L1 expression in small cell neuroendocrine carcinomas. Eur. J. Cancer 2015, 51, 421-426. [CrossRef] [PubMed] 
12. Alexandrov, L.B.; Nik-Zainal, S.; Wedge, D.C.; Aparicio, S.A.J.R.; Behjati, S.; Biankin, A.V.; Bignell, G.R.; Bolli, N.; Borg, A.; Børresen-Dale, A.L.; et al. Signatures of mutational processes in human cancer. Nature 2013, 500, 415-421. [CrossRef]

13. Graus, F.; Dalmau, J.; Reñé, R.; Tora, M.; Malats, N.; Verschuuren, J.J.; Cardenal, F.; Viñolas, N.; Garcia del Muro, J.; Vadell, C.; et al. Anti-Hu antibodies in patients with small-cell lung cancer: Association with complete response to therapy and improved survival. J. Clin. Oncol. 1997, 15, 2866-2872. [CrossRef]

14. Pelosof, L.C.; Gerber, D.E. Paraneoplastic syndromes: An approach to diagnosis and treatment. Mayo Clin. Proc. 2010, 85, 838-854. [CrossRef]

15. Facchinetti, F.; Marabelle, A.; Rossi, G.; Soria, J.C.; Besse, B.; Tiseo, M. Moving immune checkpoint blockade in thoracic tumors beyond NSCLC. J. Thorac. Oncol. 2016, 11, 1819-1836. [CrossRef]

16. Antonia, S.J.; López-Martin, J.A.; Bendell, J.; Ott, P.A.; Taylor, M.; Eder, J.P.; Jäger, D.; Pietanza, M.C.; Le, D.T.; de Braud, F; et al. Nivolumab alone and nivolumab plus ipilimumab in recurrent small-cell lung cancer (CheckMate 032): A multicentre, open-label, phase 1/2 trial. Lancet Oncol. 2016, 17, 883-895. [CrossRef]

17. Reck, M.; Vicente, D.; Ciuleanu, T.; Gettinger, S.; Peters, S.; Horn, L.; Audigier-Valette, C.; Pardo, N.; Juan-Vidal, O.; Cheng, Y.; et al. Efficacy and safety of nivolumab (nivo) monotherapy versus chemotherapy (chemo) in recurrent small cell lung cancer (SCLC): Results from CheckMate 331. Ann. Oncol. 2018, 29 (Suppl. 10), X43. [CrossRef]

18. Pujol, J.L.; Greillier, L.; Audigier-Valette, C.; Moro-Sibilot, D.; Uwer, L.; Hureaux, J.; Guisier, F.; Carmier, D.; Madelaine, J.; Otto, J.; et al. A randomized non-comparative phase II study of anti-programmed cell death-ligand 1 atezolizumab or chemotherapy as second-line therapy in patients with small cell lung cancer: Results from the IFCT-1603 trial. J. Thorac. Oncol. 2019, 14, 903-913. [CrossRef]

19. Gadgeel, S.M.; Pennell, N.A.; Fidler, M.J.; Halmos, B.; Bonomi, P.; Stevenson, J.; Schneider, B.; Sukari, A.; Ventimiglia, J.; Chen, W.; et al. Phase II Study of Maintenance Pembrolizumab in Patients with Extensive-Stage Small Cell Lung Cancer (SCLC). J. Thorac. Oncol. 2018, 13, 1393-1399. [CrossRef]

20. Ready, N.; Farago, A.F.; de Braud, F.; Atmaca, A.; Hellmann, M.D.; Schneider, J.G.; Spigel, D.R.; Moreno, V.; Chau, I.; Hann, C.L.; et al. Third-Line Nivolumab Monotherapy in Recurrent SCLC: CheckMate 032. J. Thorac. Oncol. 2019, 14, 237-244. [CrossRef]

21. Chung, H.C.; Piha-Paul, S.A.; Lopez-Martin, J.; Schellens, J.H.M.; Kao, S.; Miller, W.H.; Delord, J.P.; Gao, B.; Planchard, D.; Gottfried, M.; et al. Pembrolizumab After Two or More Lines of Previous Therapy in Patients With Recurrent or Metastatic SCLC: Results From the KEYNOTE-028 and KEYNOTE-158 Studies. J. Thorac. Oncol. 2020, 15, 618-627. [CrossRef] [PubMed]

22. Horn, L.; Mansfield, A.S.; Szczęsna, A.; Havel, L.; Krzakowski, M.; Hochmair, M.J.; Huemer, F.; Losonczy, G.; Johnson, M.L.; Nishio, M.; et al. First-line atezolizumab plus chemotherapy in extensive-stage small-cell lung cancer. N. Engl. J. Med. 2018, 379, 2220-2229. [CrossRef]

23. Paz-Ares, L.; Dvorkin, M.; Chen, Y.; Reinmuth, N.; Hotta, K.; Trukhin, D.; Statsenko, G.; Hochmair, M.J.; Özgüroğlu, M.; Ji, J.H.; et al. Durvalumab plus platinum-etoposide versus platinum-etoposide in first-line treatment of extensive-stage small-cell lung cancer (CASPIAN): A randomised, controlled, open-label, phase 3 trial. Lancet 2019, 394, 1929-1939. [CrossRef]

24. Rudin, C.M.; Awad, M.M.; Navarro, A.; Gottfried, M.; Peters, S.; Csőszi, T.; Cheema, P.K.; Rodriguez-Abreu, D.; Wollner, M.; Yang, J.C.-H.; et al. Pembrolizumab or placebo plus etoposide and platinum as first-line therapy for extensive-stage small-cell lung cancer. J. Clin. Oncol. 2020, 38, 2369-2379. [CrossRef]

25. Mansfield, A.S.; Każarnowicz, A.; Karaseva, N.; Sánchez, A.; De Boer, R.; Andric, Z.; Reck, M.; Atagi, S.; Lee, J.S.; Garassino, M.; et al. Safety and patient-reported outcomes of atezolizumab, carboplatin, and etoposide in extensive-stage small-cell lung cancer (IMpower133): A randomized phase I/III trial. Ann. Oncol. 2020, 31, 310-317. [CrossRef]

26. Reck, M.; Liu, S.V.; Mansfield, A.S.; Mok, T.S.K.; Scherpereel, A.; Reinmuth, N.; Garassino, M.C.; De Carpeno, Jc.; Califano, R.; Nishio, M.; et al. IMpower133: Updated overall survival (OS) analysis of first-line (1L) atezolizumab (atezo) + carboplatin + etoposide in extensive-stage SCLC (ES-SCLC). Ann. Oncol. 2019, 30 (Suppl. 5), V710-V711. [CrossRef]

27. Paz-Ares, L.; Dvorkin, M.; Chen, Y.; Reinmuth, N.; Hotta, K.; Trukhin, D.; Statsenko, G.; Hochmair, M.J.; Özgüroğlu, M.; Ji, J.H.; et al. Durvalumab +/-tremelimumab + platinum-etoposide in first-line extensive-stage SCLC (ES-SCLC): Updated results from the phase III CASPIAN study. J. Clin. Oncol. 2020, 38, 9002. [CrossRef] 
28. Rudin, C.M.; Awad, M.M.; Navarro, A.; Gottfried, M.; Peters, S.; Csőszi, T.; Cheema, P.K.; Rodriguez-Abreu, D.; Wollner, M.; Yang, J. C-H.; et al. KEYNOTE-604: Pembrolizumab (pembro) or placebo plus etoposide and platinum (EP) as first-line therapy for extensive-stage (ES) small-cell lung cancer (SCLC). J. Clin. Oncol. 2020, 38, 9001. [CrossRef]

29. Leal, T.; Wang, Y.; Dowlati, A.; DeQuincy, A.L.; Chen, Y.; Mohindra, A.R.; Razaq, M.; Ahuja, H.G.; Liu, J.; King, D.M.; et al. Randomized phase II clinical trial of cisplatin/carboplatin and etoposide (CE) alone or in combination with nivolumab as frontline therapy for extensive-stage small cell lung cancer (ES-SCLC): ECOG-ACRIN EA5161. J. Clin. Oncol. 2020, 38, 9000. [CrossRef]

30. Ferrara, R.; Pilotto, S.; Caccese, M.; Grizzi, G.; Sperduti, I.; Giannarelli, D.; Milella, M.; Besse, B.; Tortora, G.; Bria, E. Do immune checkpoint inhibitors need new studies methodology? J. Thorac. Dis. 2018, 10, S1564-S1580. [CrossRef]

31. Hellmann, M.D.; Callahan, M.K.; Awad, M.M.; Calvo, E.; Ascierto, P.A.; Atmaca, A.; Rizvi, N.A.; Hirsch, F.R.; Selvaggi, G.; Szustakowski, J.D.; et al. Tumor mutational burden and efficacy of nivolumab monotherapy and in combination with ipilimumab in small-cell lung cancer. Cancer Cell 2018, 35, 329. [CrossRef] [PubMed]

32. Ricciuti, B.; Kravets, S.; Dahlberg, S.E.; Umeton, R.; Albayrak, A.; Subegdjo, S.J.; Johnson, B.E.; Nishino, M.; Sholl, L.M.; Awad, M.M. Use of targeted next generation sequencing to characterize tumor mutational burden and efficacy of immune checkpoint inhibition in small cell lung cancer. J. Immunother. Cancer 2019, 7, 87. [CrossRef]

33. Rudin, C.M.; Poirier, J.T.; Byers, L.A.; Dive, C.; Dowlati, A.; George, J.; Heymach, J.V.; Johnson, J.E.; Lehman, J.M.; MacPherson, D.; et al. Molecular subtypes of small cell lung cancer: A synthesis of human and mouse model data. Nat. Rev. Cancer 2019, 19, 289-297. [CrossRef]

34. Konstantina, T.; Konstantinos, R.; Anastasios, K.; Anastasia, M.; Eleni, L.; Ioannis, S.; Sofia, A.; Dimitris, M. Fatal adverse events in two thymoma patients treated with anti-PD-1 immune check point inhibitor and literature review. Lung Cancer 2019, 135, 29-32. [CrossRef]

35. Steffens, C.C.; Elender, C.; Hutzschenreuter, U.; Dille, S.; Binninger, A.; Spring, L.; Jänicke, M.; Marschner, N. Treatment and outcome of 432 patients with extensive-stage small cell lung cancer in first, second and third line - Results from the prospective German TLK cohort study. Lung Cancer 2019, 130, 216-225. [CrossRef]

36. Cramer-van der Welle, C.M.; Schramel, F.M.N.H.; van Leeuwen, A.S.; Groen, H.J.M.; van de, G.E. Real-world treatment patterns and outcomes of patients with extensive disease small cell lung cancer. Eur. J. Cancer Care 2020, 14. [CrossRef] [PubMed]

37. Tendler, S.; Zhan, Y.; Pettersson, A.; Lewensohn, R.; Viktorsson, K.; Fang, F. DPL Treatment patterns and survival outcomes for small-cell lung cancer patients - a swedish single center cohort study. Acta Oncol. 2020, 59, 388-394. [CrossRef]

38. Seute, T.; Leffers, P.; Ten Velde, G.P.M.; Twijnstra, A. Neurologic disorders in 432 consecutive patients with small cell lung carcinoma. Cancer 2004, 100, 801-806. [CrossRef]

39. Arbour, K.C.; Mezquita, L.; Long, N.; Rizvi, H.; Auclin, E.; Ni, A.; Martínez-Bernal, G.; Ferrara, R.; Victoria Lai, W.; Hendriks, L.E.L.; et al. Impact of baseline steroids on efficacy of programmed cell death-1 and programmed death-ligand 1 blockade in patients with non-small-cell lung cancer. J. Clin. Oncol. 2018, 36, 2872-2878. [CrossRef]

40. Piedbois, P.; Buyse, M. Meta-analyses based on abstracted data: A step in the right direction, but only a first step. J. Clin. Oncol. 2004, 22, 3839-3841. [CrossRef] [PubMed]

41. Available online: https://www.medcalc.org/calc/comparison_of_proportions.php (accessed on 5 June 2020).

42. Mak, D.W.S.; Li, S.; Minchom, A. Challenging the recalcitrant disease-developing molecularly driven treatments for small cell lung cancer. Eur. J. Cancer 2019, 119, 132-150. [CrossRef] [PubMed]

(C) 2020 by the authors. Licensee MDPI, Basel, Switzerland. This article is an open access article distributed under the terms and conditions of the Creative Commons Attribution (CC BY) license (http://creativecommons.org/licenses/by/4.0/). 